\title{
FutureJournal
}

\section{A Mobilidade e a Sobrecarga de Comunicação nos Profissionais do Mercado Financeiro: Quanto mais, melhor?}

\section{Carla Bonato Marcolin}

Doutoranda em Administração pela Universidade Federal do Rio Grande do Sul (UFRGS), Brasil

cbmarcolin@gmail.com

\section{Henrique Melo Rodrigues de Freitas}

Doutor em Administração pela Universidade Pierre Mendès-France, França freitas138@gmail.com

\section{Ariel Behr}

Doutor em Administração pela Universidade Federal do Rio Grande do Sul (UFRGS), Brasil behr.ariel@gmail.com

\section{Cristina Dai Prá Martens}

Doutora em Administração pela Universidade Federal do Rio Grande do Sul (UFRGS), Brasil cristinadpmartens@gmail.com

\section{RESUMO}

O ambiente organizacional está cada vez mais embebido em tecnologias, e as tecnologias móveis, posicionadas nesse ambiente, são tecnologias que transformam o cenário dos gestores, trazendo facilidades e desafios ao mesmo tempo. A intensa integração de suas atividades com as tecnologias móveis apresenta alta conectividade e disponibilidade. O dispositivo apresenta-se como uma porta aberta, pela qual os profissionais estão sempre disponíveis para contato, queiram ou não. Neste estudo, procurouse compreender a sobrecarga de comunicação através das tecnologias móveis nas tarefas profissionais. Por meio de um estudo com 11 profissionais do mercado financeiro, foi possível aprofundar alguns seus aspectos, sendo o de notificações instantâneas o mais comentado, não apenas no âmbito profissional mas também no âmbito pessoal. Também houve destaque para os impactos do fato de se estar sempre conectado, e de que a própria tecnologia entrega formas de gerenciar as questões por ela mesma criadas.

PALAVRAS-ChAVE: Tecnologias móveis. Sobrecarga de comunicação. Profissionais financeiros. 


\section{FutureJournal}

\section{Mobility and Communication Overload in Financial Market \\ Professionals: The more the better?}

\section{ABSTRACT}

The organizational environment is increasingly embedded with technologies, and mobile technologies, positioned in this environment, are ones that transform the landscape of managers, bringing facilities and challenges at the same time. The intense integration of their activities with mobile technologies brings high connectivity and availability. The device is presented as an open door through which professionals are always available to contact, regardless of their choice. This study sought to understand the communication overload through mobile technologies within the professional's tasks. Through a study with 11 financial market professionals, it was possible to deepen in some aspects, with the instant notifications being the most talked about, not only in the professional but also on a personal level. There was also emphasis on the impacts of the fact about being constantly connected, and that technology ends up to deliver own ways of managing the issues that it has itself raised.

KEY-WORDS: Mobile technologies. Communication overload. Financial professional. 


\section{INTRODUÇÃO}

Apesar dos diversos nomes (computação ubíqua, Weiser, 1991; computação pervasiva, Ark \& Selker, 1999; tecnologias móveis, Saccol \& Reinhard, 2007), a centralidade da ideia desses conceitos - diferentes, porém com a mesma essência - é evidenciar o fato de a tecnologia estar presente de maneira massiva na vida dos indivíduos e das organizações. Já é realidade o fato de que se convive com mais dispositivos móveis do que pessoas no planeta (Forbes, 2013). Com cada vez mais conectividade, surgem novas possibilidades de comunicar-se e interagir.

Essa configuração comunicacional borra as fronteiras, permitindo uma nova relação com o tempo, com o espaço e com diversos territórios (Lemos, 2007). Os acontecimentos são internacionais, independentemente de onde aconteçam, pois podem ser transmitidos ao vivo de qualquer lugar para um dispositivo que cabe na palma da mão. Novas formas de trabalho individual ou em equipe, propiciadas pela internet e mais ainda pelo dispositivo móvel mudam bastante o ambiente organizacional e sua operação: ao natural, esse recurso tecnológico passa a estar presente em todos os níveis da organização (Sorensen, 2010).

Estar sempre conectado permite também o envolvimento com outras pessoas ou com diferentes atividades, em espaços de tempo que antes não eram utilizados. Ao mesmo tempo, faz com que os indivíduos estejam sempre disponíveis para serem contatados (Bittman, Brown \& Wajcman, 2009). Com isso, é praticamente instantânea a tomada de conhecimento sobre qualquer novidade. A vantagem de deter uma informação é algo muito volátil (Póvoa, 2010): um exemplo é a oscilação ou correção dos preços das ações, afetados pela intensidade de informações que facilmente transitam.

Pesquisar sobre tais temáticas pode agregar a compreensão de como os profissionais da área de finanças enxergam esse fenômeno da alta disponibilidade. Afinal, nesse contexto, insere-se a queda de rendimento do mercado de capitais (Folha de S.Paulo, 2013), e, numa tentativa de reter sua clientela, os operadores do mercado financeiro passaram a oferecer uma mais ampla gama de produtos visando a perfis diversos. 
O profissional financeiro é, portanto, aquele que presta serviços financeiros, de qualquer natureza. Adicionando-se o aumento da variedade de serviços e, especialmente, produtos diferentes a ofertar (Hadar, Sood \& Fox, 2013), é notável o escopo significativamente amplo e crescente da profissão. Além disso, a informação, matéria-prima neste mercado, transforma-se cada vez mais em commodity devido à simetria temporal causada pela internet (Póvoa, 2010). Tudo isso exige que o perfil do profissional atuante nessa área se transforme do reativo ao proativo e seja também multidisciplinar (IBCPF, 2013), pois, além de necessitar conhecer os diversos produtos de investimento, também deverá gerenciar os diferentes perfis de clientes e manter-se atualizado em um mercado dinâmico.

Assim, para atuar na área, esse profissional enfrenta diversos desafios, dada a expressiva expansão do escopo do uso de tecnologias móveis, sendo-lhe importante compreender mais sobre esse processo (Dourish, 2004). Em função das diversas funcionalidades dessas tecnologias, nota-se que as fronteiras entre horário de trabalho e horário de lazer ficam menos nítidas e imbricadas em uma mesma tela. Sempre conectados, os profissionais podem ser acessados por qualquer pessoa de sua rede de contatos a qualquer momento, independentemente de sua escolha. Assim, o objetivo neste artigo é analisar como os profissionais percebem e lidam com a sobrecarga de comunicação possibilitada pelos dispositivos móveis. Para isso, foram observados e entrevistados 11 profissionais do mercado financeiro.

Na revisão da literatura, aprofundam-se os principais aspectos da pesquisa, finalizando-se com a dimensão de sobrecarga de comunicação. 0 método é apresentado na seção posterior, e finalmente são apresentados os resultados e as conclusões.

\section{REVISÃO DA LITERATURA}

Devido à intensa adoção dos recursos de tecnologia móvel presente no ambiente organizacional, é importante compreender como esses dispositivos são utilizados e como impactam o dia a dia dos profissionais 
(Pica, Sorensen \& Allen, 2004). Afinal, essas mesmas tecnologias, responsáveis por entregar mais possibilidades, trazem impactos positivos e negativos, conceitualmente inseparáveis (Jarvenpaa \& Lang, 2005). Dessa maneira, de forma a cultivar o sucesso na interação com as tecnologias móveis, é preciso refletir sobre o contexto de uso.

\subsection{O AMBIENTE DOS GESTORES: AS TECNOLOGIAS MÓVEIS}

Tecnologias móveis são dispositivos portáteis de tecnologia da informação, que podem, pois, ser levados para qualquer lugar, criando assim ambientes virtuais em ambientes reais (Pica et al., 2004; Saccol \& Reinhard, 2007).

Porém o conceito de mobilidade pode ir além de uma característica da tecnologia e ser discutido de maneira a observar a independência do limite das fronteiras, e não apenas das geográficas. Kakihara e Sorensen (2001) argumentam que o "ser móvel" está ligado de maneira mais relevante com a interação entre as pessoas, sugerindo a expansão do conceito de mobilidade através das dimensões de espaço, tempo e contexto. Afinal, essas dimensões foram fortemente modificadas devido ao uso dessas tecnologias (Kakihara \& Sorensen, 2001).

Permitindo interação com um ambiente virtual, os dispositivos móveis trazem embarcados diversos recursos multimídia, podendo atuar como rádio, televisão, jornal e GPS, tudo ao mesmo tempo (Schroeder, 2010; Zhong, 2013). Com isso, trazem maior facilidade de acesso a qualquer pessoa, a qualquer hora e em qualquer lugar, gerando mudança social e modificação na forma de agir (Pica et al., 2004; Schroeder, 2010). Portanto, esse olhar a respeito das tecnologias que não apenas se movem, mas também transformam por permitirem mobilidade, é o aspecto de interesse deste estudo.

A visão de informação como importante ferramental do "gerente", juntamente com a noção do tempo como recurso "perecível e evanescente" já eram destacadas por Drucker (1970). Por sua vez, Mintzberg (1984) demonstrou que os gestores seriam submetidos a pressões cada vez maiores, dadas suas diversas responsabilidades (ou papéis), ao mesmo 
tempo em que seriam expostos a uma complexidade crescente dentro e fora das organizações.

Porém, inovações significativas como a internet e as tecnologias móveis, que vêm modificando a forma como as organizações - e seus gestores - operam, contribuem para o aumento dessa complexidade de forma significativa, uma vez que trazem consigo um conjunto de desafios único e bastante particular (Ladd, Datta, Sarker \& Yu, 2010). Ao permitir que se distribuam atividades em diferentes locais e que os processos possam ser executados e coordenados independentemente das fronteiras de tempo e distância, a tecnologia não pode mais ser separada da gestão da organização, uma vez que já está imbricada no ambiente, caracterizando-o como ecossistema de negócios digital (Bharadwaj, Sawy, Pavlou \& Venkatraman, 2013).

Além disso, trazer essas tecnologias como impulsionadoras de um ritmo mais intenso do cotidiano desse gestor pode não ser adequado, mas a possibilidade de uso em espaços paralelos para aproveitamento do tempo em carros, cafés e aeroportos pode aumentar a sensação de falta de tempo (Bittman et al., 2009) e de ansiedade pela conexão constante (Mazmanian, Orlikowski \& Yates, 2005), por exemplo. Dessa maneira, o gestor, ao mesmo tempo que pode ter a necessidade de uso das tecnologias móveis por serem meios de interação imediata, atendendo a uma demanda de atuação naquele momento, também poderá estar exposto a situações de pressão pela constante conexão e interação entre seus diversos papéis.

Simplesmente medir o tempo de uso pode não captar sua relação com os resultados esperados (DeLone \& McLean, 2003). Alto nível de uso de um smartphone, por exemplo, pode ser devido à verificação de e-mails, mensagens para familiares ou atualização de redes sociais; ou todas essas atividades em paralelo, cada uma com diferentes níveis de energia do usuário. Assim, os dispositivos permitem que os gestores sejam cada vez mais multitarefa, misturando os diversos aspectos da vida dos indivíduos. De forma a compreender melhor o que significa esse uso, a próxima seção aprofunda o conceito e detalha como seus elementos serão trabalhados neste estudo. 


\subsection{SOBRECARGA DO USO DE TECNOLOGIA}

Todos esses desafios fazem parte da transformação do ambiente organizacional produzida pelas tecnologias móveis. Com o aumento da inserção dessas tecnologias no cenário das empresas, de forma a suportar o trabalho de seus profissionais, torna-se relevante compreender como essas tecnologias participam da rotina dos profissionais (Pica et al., 2004). Elas são responsáveis por entregar mais possibilidades, trazendo impactos de diferentes naturezas, que não são passíveis de separar na realidade (Jarvenpaa \& Lang, 2005). A possibilidade de estar constantemente conectado gera um ciclo de expectativas que podem tornar-se normas sociais coercitivas (Mazmanian et al., 2005) e inclusive levar a frequentes impulsos e criação de vínculos viciosos com a tecnologia em uso (Jarvenpaa \& Lang, 2005).

Para trabalhar com a intensa integração das tecnologias móveis junto aos profissionais, partiu-se do conceito de sobrecarga do uso de tecnologia, de Karr-Wisniewski e Lu (2010). Essa sobrecarga refere-se ao aumento do uso da tecnologia além do nível produtivo - o que provocaria uma queda na curva tecnologia versus produtividade. As autoras realizaram um estudo em que abordam o uso da tecnologia dentro das organizações e cujo objetivo principal é analisar a sobrecarga de tecnologia (technology overload) à qual os profissionais estão expostos (Eppler \& Mengis, 2004; Karr-Wisniewski \& Lu, 2010).

Pesquisas preocupadas com essa sobrecarga concentram-se em esclarecer causas, consequências e soluções para situações nas quais há muita informação sendo recebida (Eppler \& Mengis, 2004) inclusive na "ponta dos dedos" (Davenport \& Beck, 2002). O contexto móvel é formado por situações como essas, nas quais as novas tecnologias de informação, ao mesmo tempo que provêm conveniente acesso à informação, facilitam o recebimento da mesma, importante ou não, solicitada ou não (Bawden \& Robinson, 2009).

As autoras propuseram uma construção teórica composta por três dimensões: sobrecarga de recursos, sobrecarga de informação e sobrecarga de comunicação (Karr-Wisniewski \& Lu, 2010). O objetivo neste artigo é, 
portanto, investigar a sobrecarga de comunicação, uma vez que esta trabalha com a alta conectividade e a disponibilidade a que os profissionais estão expostos, lançando um olhar mais reflexivo a respeito do papel das tecnologias móveis no contexto dos gestores.

\subsubsection{Sobrecarga de comunicação}

A sobrecarga de comunicação (communication overload) aborda o excesso de comunicação que parte de outrem e que gera interrupção na atividade. Segundo a lei de Yerkes e Dodson (1908, citados por KarrWisniewski \& Lu, 2010) a performance dos indivíduos tende a crescer com distrações por aumentar o foco na primeira tarefa, porém apenas até certo ponto. Cohen (1980) completa relatando que muitas vezes os efeitos na performance conseguem ser verificados apenas após o término do fato provocador - no caso, a interrupção - e que essas distrações podem levar a impactos negativos, como a diminuição da produtividade, devido ao esforço cognitivo de retomar a atividade.

A interrupção pode ter outros pontos de partida, além de outra pessoa. Essa discussão pode ser estendida no sentido de trazer elementos da própria tecnologia como influenciadores na relação entre os indivíduos e seu ambiente de trabalho (Pica et al., 2004).

Os profissionais, especialmente aqueles que lidam com informação de maneira intensa, estão inseridos em um ambiente de trabalho com diversos meios de comunicação, como e-mail, mensagens instantâneas, comunicação via VOIP, acesso a um computador (desktop ou notebook), além de um dispositivo móvel, com mais tantas outras opções. Com esse cenário, há a preocupação de que a proliferação de comunicação possa levar a uma rotina de trabalho fragmentada, com interrupções frequentes entre as tarefas (Bittman et al., 2009). Sandi e Saccol (2010) também trazem a discussão a respeito da interrupção. Em pesquisa com profissionais de vendas, as autoras demonstraram a sensação de frequente dificuldade de retomada da concentração após uma interrupção (como ligações telefônicas e SMS) (Sandi \& Saccol, 2010). 
A interrupção tem como um dos pontos de partida a constante disponibilidade que o dispositivo móvel propicia. Yun, Kettinger e Lee (2012) retratam esse cenário por meio da figura de linguagem da porta de um escritório: ao estar aberta, demonstra que há disponibilidade para interação com os demais colegas. O dispositivo móvel, por meio de seus recursos, fez com que a porta estivesse permanentemente aberta, ou seja, a qualquer momento é possível ser interpelado, seja através de uma ligação, mensagem, e-mail, ou qualquer outra forma de comunicação (Yun et al., 2012).

Destaca-se, assim, um ponto duplo do dispositivo: ao permitir a mobilidade, por entregar ao indivíduo a liberdade de mover-se e, como uma ponte, fazer com que o que está distante fique mais presente (Pica et al., 2004), acaba também trazendo a contrapartida de uma disponibilidade instantânea para qualquer requisição de interação, seja ela oportuna ou não (Sorensen, 2010).

O equilíbrio entre os dois lados dessa ponte é dinâmico, por envolver diversos aspectos. Não apenas motivações de quem quer contatar e de quem é contatado independentemente de solicitação, mas também pontos da própria tecnologia. Sorensen (2010) argumenta que a tecnologia móvel precisa estar dentro dessa análise, pois seus recursos podem permitir maior harmonia na interação de constante disponibilidade. Afinal, é a própria tecnologia que está mediando essas interações. O autor caracteriza essa mediação como simétrica e assimétrica.

A simetria da relação implica que a tecnologia não irá prover nenhum tipo de diferença entre as partes. Assim, uma mensagem do tipo SMS, por exemplo, em condições adequadas de conexão e funcionamento, sempre chegará a seu destinatário, muitas vezes em fração de segundos. Mas não será possível informar se aquela mensagem é desejada, oportuna para aquele momento ou qualquer outra forma de interceptação em seu fluxo, por nenhuma das partes. Características de assimetria, por sua vez, vão determinar que a tecnologia móvel entregará recursos cujas regras permitam transformar essa interação. Recursos como filtros e listas de contatos com regras específicas podem determinar desde um toque diferente até o bloqueio do recebimento dos contatos. Dessa forma, os 
indivíduos podem melhor gerir as interações mediadas pela tecnologia móvel (Sorensen, 2010).

Orlikowski (2007) demonstra em seus estudos que os portadores de BlackBerry de uma empresa de investimentos relataram a necessidade de permanecer sempre a par do que estava acontecendo através de checagem constante de seus e-mails, a qualquer hora do dia ou da noite. Como, dentre o grupo em questão, sabia-se que todos possuíam o aparelho, havia uma expectativa de acompanhamento constante, elevando o nível de expectativa de resposta, também de forma constante. Através desse movimento, a ação das pessoas em relação ao aparelho e a seu uso transforma-se a partir de sua interação, transformando algo, no caso a leitura dos e-mails, de esporádico para frequente e esperado pelos pares no ambiente de trabalho (Mazmanian, Orlikowski \& Yates, 2006).

A construção da expectativa da resposta é, portanto, um fator importante. Através dela, é possível perceber que uma ação incomum pode passar a ser incorporada de forma natural, e até mesmo torna-se generalizada. Assim, o uso desse artefato, que até então não fazia parte da realidade, passa a ser transformado em um estilo reconhecido (por ex.: "usuário crônico") (Orlikowski, 2007) e que muda inclusive a forma de ver os outros (uma vez que desse usuário espera-se sempre uma pronta resposta).

Assim, diversas questões estão envolvidas neste cenário, quanto ao uso da tecnologia móvel. A característica multitarefa dos dispositivos móveis trata não apenas da alta quantidade de recursos entregues pela tecnologia disponíveis na palma da mão. Existem diferentes possibilidades, que dependem ou não do usuário, nos dispositivos móveis. É possível interromper uma atividade de maneira ativa ou passiva, com o mesmo dispositivo. As ferramentas de push notifications fazem surgir na tela informações, sejam elas desejáveis ou não (Eppler \& Mengis, 2004; Bawden \& Robinson, 2009). Dado um ambiente em transformação e cada vez mais exigente (Póvoa, 2010), os profissionais precisam lidar com as diversas questões advindas da tecnologia móvel.

As diversas possibilidades, e as diferentes reflexões acerca de seus reflexos positivos e negativos, estão relacionadas com o que foi 
previamente exposto. Acredita-se que estudar a sobrecarga de comunicação possa auxiliar a ler o ambiente, possibilitando olhares críticos em relação às tecnologias móveis.

\section{MÉTODO}

Por ser um estudo que buscou percepções a respeito do ambiente da problemática exposta, quanto ao método, esta pesquisa caracteriza-se como qualitativa. Para atingir o objetivo proposto, os dados foram coletados por meio da realização de observação direta e de entrevistas semiestruturadas em profundidade (Malhotra, 2012; Yin, 2010) junto a profissionais do mercado financeiro certificados pela Associação Brasileira das Entidades dos Mercados Financeiro e de Capitais (Anbima), constituindo estes a unidade de análise. Seguindo-se o sugerido por Büscher e Urry (2009), para agregar na análise dos dados, foi mantido um diário de campo, que auxiliou na memória da pesquisa. Assim, as conclusões do estudo podem se estabelecer de maneira mais acurada, possibilitando abordagem de um maior número de aspectos na análise dos dados (Yin, 2010), dada a combinação de mais de uma fonte de dados, o que aumenta substancialmente a qualidade da coleta, permitindo a convergência de diferentes dados para análise dos mesmos fatos.

Ao total, 11 profissionais participaram da pesquisa, todos com pelo menos uma das certificações oferecidas pela Anbima; sete deles possuem adicionalmente a certificação do Instituto Brasileiro de Certificação de Profissionais Financeiros (IBCPF), denominada Certificação de Profissional Financeiro, comumente chamada de CFP. A certificação do IBCPF permitiu localizar esses profissionais por meio do site da instituição, também importante para abordar profissionais que não apenas comercializam os produtos disponíveis, como também atuam como aconselhadores. Os demais quatro profissionais foram localizados através do site da Comissão de Valores Mobiliários (CVM), da Anbima e de contatos profissionais, sempre respeitando o perfil definido a priori.

A coleta dos dados iniciou-se pelos dados sociodemográficos, seguidos do questionamento sobre o uso de tecnologia e pela observação 
direta. No final, foi realizada a entrevista cujo roteiro semiestruturado encontra-se no Quadro 1.

Em relação aos dados sociodemográficos, sempre que possível, procurou-se identificar, ao invés de perguntar, as respostas das questões. Também procurou-se obter do entrevistado informações acerca do uso de tecnologias móveis, o que era indispensável para participação da pesquisa.

A observação direta seguiu um protocolo previamente definido e ocorreu antes da entrevista, possibilitando aprofundamento de outros aspectos observados ao longo da sessão. Para observar de que forma a tecnologia móvel estaria sendo utilizada no ambiente de trabalho, solicitouse aos participantes que se pudesse acompanhá-los durante um período de tempo (entre meio turno e um turno, ou seja, de duas a quatro horas).

Após a observação direta, foram realizadas as entrevistas. Elas foram gravadas e seu objetivo foi verificar como o entrevistado lida com os aspectos da sobrecarga de comunicação e como esta se manifesta em sua realidade. O roteiro das entrevistas foi elaborado com base na literatura destacada. As perguntas foram realizadas conforme o aspecto que mais se destacava, assim, a pesquisadora procurou estar mais focada em abordar todo o conteúdo do que em respeitar a ordem do roteiro elaborado, uma vez que as entrevistas foram semiestruturadas.

\begin{tabular}{|c|c|c|}
\hline Dimensão & Aspecto & Questão \\
\hline \multirow{5}{*}{$\begin{array}{l}\text { Sobrecarga } \\
\text { de } \\
\text { Comunicação }\end{array}$} & $\begin{array}{l}\text { Conexão } \\
\text { Constante }\end{array}$ & $\begin{array}{l}\text { Qual a sua opinião sobre a conexão constante (por exemplo, } \\
\text { e-mail sempre disponível) proporcionada pela TI móvel? } \\
\text { (Sorensen, 2010; Yun et al., 2012) }\end{array}$ \\
\hline & $\begin{array}{l}\text { Conexão } \\
\text { Constante }\end{array}$ & $\begin{array}{l}\text { Se você ficar sem internet em seu dispositivo móvel, sente-se } \\
\text { mais ou menos produtivo? Por quê? (Sorensen, 2010) }\end{array}$ \\
\hline & $\begin{array}{l}\text { Notificações } \\
\text { Instantâneas }\end{array}$ & $\begin{array}{l}\text { Você acredita que seja importante, de alguma forma, filtrar a } \\
\text { comunicação que recebe através de seu dispositivo móvel } \\
\text { (recursos de bloqueio, toques diferentes)? Por quê? } \\
\text { (Sorensen, 2010) }\end{array}$ \\
\hline & $\begin{array}{l}\text { Notificações } \\
\text { Instantâneas }\end{array}$ & $\begin{array}{l}\text { Ao receber um alerta, no seu dispositivo móvel, de origem } \\
\text { profissional, acredita que seja importante responder no } \\
\text { mesmo momento? Poderia explicar? (Mazmanian et al.; 2006) }\end{array}$ \\
\hline & $\begin{array}{l}\text { Notificações } \\
\text { Instantâneas }\end{array}$ & $\begin{array}{l}\text { Você acredita que as notificações instantâneas em seu } \\
\text { dispositivo de TI móvel sejam importantes? Como elas afetam } \\
\text { sua concentração? (Sandi \& Saccol, 2010; Yun et al., 2012) }\end{array}$ \\
\hline
\end{tabular}




\section{Quadro 1: Roteiro das entrevistas semiestruturadas}

Fonte: Elaborado pelos autores

Após a realização das entrevistas e das observações diretas, os dados foram transcritos por um dos autores no editor de texto Word. Houve - cuidado de realizar a transcrição perto da data de realização da observação e da entrevista, recurso que permitiu, durante esse processo, rememorar e familiarizar-se com os dados. A transcrição foi realizada de forma individual (por profissional), resultando no final 11 transcrições completas.

Os dados foram analisados a partir dos aspectos propostos no estudo. No geral, a sobrecarga de comunicação abordou a disponibilidade e a conexão constante que o dispositivo móvel traz, sendo o foco aquela comunicação que se inicia por um terceiro, e não pelo próprio indivíduo. 0 objetivo da análise dos dados foi conseguir captar, através dos dados que estavam disponíveis (entrevistas e relatos da observação direta), o que realmente foi expresso, mesmo que de maneira indireta (Freitas \& Moscarola, 2002). Durante a leitura, foram anotadas algumas palavras relevantes - por aparecerem de forma frequente ou por relação com o aspecto da dimensão em questão. Com essas anotações, procedeu-se à navegação lexical, assim, foi possível ter uma ideia geral de todos os textos em conjunto e procurou-se identificar os contextos dessas palavras selecionadas. Esse processo foi seguido da análise de conteúdo dos textos, através de rodadas de leitura cuidadosas, de forma a tomar conhecimento do que foi dito e observado e enriquecer a interpretação (Freitas \& Moscarola, 2002).

\section{RESULtAdOS}

A seção a seguir apresenta os resultados deste estudo. Primeiramente, são detalhados o ambiente e os profissionais participantes desta pesquisa, focando nos tipos de organizações visitadas e o perfil dos 11 participantes. Em seguida, são apresentados os resultados acerca da sobrecarga de comunicação. 


\subsection{O AMBIENTE DOS PROFISSIONAIS DO MERCADO FINANCEIRO}

Onze profissionais do mercado financeiro participaram da pesquisa. As organizações visitadas e a respectiva codificação utilizada foram: duas agências bancárias e uma sede bancária [BAN]; quatro corretoras de valores mobiliários [COR]; um escritório de administração de patrimônio [ESC]; e uma corretora de crédito [CCR], totalizando nove organizações. Um dos entrevistados é consultor independente [CSI], portanto não pertence a nenhuma organização específica.

Grande parte dos participantes (nove de 11) têm 30 anos ou mais, e destes três têm mais de 40 anos; trata-se, portanto, de um grupo que presenciou a crescente inserção das tecnologias móveis no mercado financeiro. Os outros dois participantes têm entre 22 e 29 anos. Dos 11 profissionais, apenas duas são mulheres. Pode-se, assim, depreender que os profissionais são em sua maioria experientes, pois sete atuam há nove anos ou mais no mercado financeiro; dentre estes, cinco trabalham há 10 anos ou mais. Porém essa experiência não se reflete em estabilidade na mesma organização: grande parte dos profissionais (oito de 11) trabalha há dois anos ou menos, e dois destes trabalham há menos de um ano na organização em que se encontravam quando da realização da pesquisa.

Todos os profissionais têm uma ou mais certificações da Anbima. Quatro participantes têm também certificações adicionais às relacionadas: três da CVM e um a certificação PQO (Programa de Qualificação Operacional), da Bovespa.

Todos os profissionais foram questionados previamente acerca de suas tarefas profissionais, seus cargos e a respeito do uso de tecnologia móvel, sendo esta última questão determinante para a participação. Dessa forma, todos relataram utilizar algum recurso de tecnologia móvel para realização de suas tarefas.

Oito dos 11 participantes utilizam tecnologia móvel pessoal para suas tarefas profissionais. Somente três participantes possuem dispositivo fornecido pela empresa, mas utilizam também seus dispositivos particulares. 
A análise em relação aos 11 participantes deu-se de forma homogênea. Poderiam ser destacadas particularidades individuais, porém este não é o principal objetivo do estudo. O que se procura é como esses participantes, que aqui representam um profissional financeiro inserido em uma realidade de mudança - especialmente em relação às novas tecnologias presentes, também, no mercado financeiro -, percebem e lidam com os desafios da sobrecarga de comunicação destacadas na literatura. No Quadro 2, resumem-se os aspectos trabalhados.

\begin{tabular}{|c|c|}
\hline Sobrecarga & Aspectos \\
\hline Sobrecarga de Comunicação & Conexão Constante e Notificações Instantâneas \\
\hline
\end{tabular}

\section{Quadro 2: Aspectos da sobrecarga de comunicação}

Fonte: Elaborado pelos autores

\subsection{SOBRECARGA DE COMUNICAÇÃO}

O profissional financeiro trata com informação de maneira intensa, lidando com dispositivos de diversas naturezas ao mesmo tempo. Essa diversificação na forma de comunicação pode estar provocando interrupções e fragmentação do trabalho, o que pode afetar aspectos como a concentração (Mazmanian et al., 2006; Sandi \& Saccol, 2010).

Além disso, compreender como os indivíduos lidam com um dispositivo que reúne diferentes aspectos (pessoais e profissionais) vem ganhando importância para as organizações, especialmente pelo potencial de influência na satisfação com o trabalho, no estresse, entre outros aspectos que podem influenciar os profissionais (Yun et al., 2012).

A sobrecarga de comunicação procurou abordar a reação e percepção dos pesquisados em relação às diversas opções de disponibilidade e comunicação - partindo de outrem - que o dispositivo móvel traz para seu cotidiano. Um dos aspectos mais comentados (por oito de 11 entrevistados) foram os sentimentos de urgência e a expectativa de resposta rápida que esta tecnologia trouxe:

[ESC] "Ninguém tem mais paciência pra esperar o cara responder 10 minutos depois, tem que ser na hora tudo. [...] Os próprios bancos hoje 
eles entram no meu Whatsapp pra me oferecer coisa. Eu tenho até que limitar. Passou do e-mail pra 'Ah, você não tava, liguei'. Não tava, o cara tá ali metralhando no Whatsapp. Assim, cara, eu tô ocupado, parece que não tem mais o cara dizer que não tá disponível. [...] Esse é um negócio curioso... Eu não sei quem veio primeiro, o ovo ou a galinha, mas as pessoas se dizem vítimas disso, mas elas fomentam isso, entendeu?"

[CSI] "Antigamente se ligava pra casa de uma pessoa, se a pessoa não tá, tá outra hora eu ligo. Hoje se liga e não atende te manda mensagem, Whatsapp, viber... inventa qualquer coisa pra te achar, tem que te achar e tu tem que responder rápido. Isso vale pra vida profissional, pra vida pessoal, tua mulher, teu marido vai te ligar e se tu não responder é porque aconteceu alguma coisa, e aí tu é cobrado, tu tem que responder rápido, se tu sai da sala e esqueceu o celular tu tem que voltar rápido porque já vai ter umas 20 necessidades que chamam. [...] Os caras não querem esperar, não querem saber se é $20 \mathrm{~h}$ da noite, se já acabou eventualmente o meu horário formal de trabalho [aspas com as mãos]. Os caras querem que meia-noite responda porque eu tenho celular pra responder."

[COR04] "Aí claro, tem a questão da urgência, desse sentimento de urgência porque... A tecnologia móvel acabou tornando as situações extremamente... tudo é urgente, tudo dá pra fazer em mobilidade. Então isso aí às vezes acaba atrapalhando, nem tudo é tão urgente assim, as vezes pode ser resolvido no seu momento normal, como se não tivesse a tecnologia móvel. [...] acaba se criando todo um sentimento de ansiedade pra todo mundo, acredito eu, que ah, aquele negócio hoje em dia tudo tem que ser resposta automática, tu já sabe se a pessoa já recebeu, se leu, se não leu, não necessariamente ela leu mas já recebeu, então eu acho que potencializou diversas situações de urgência, de ansiedade, de solução, que às vezes são boas outras vezes nem tanto."

Assim como na pesquisa de Mazmanian et al. (2006) com profissionais de um escritório de investimentos, percebe-se que boa parte dos entrevistados (oito de 11) acreditam que haja uma grande e crescente expectativa de resposta em relação aos terceiros. Com as diversas formas de contato que o dispositivo oferece, os pesquisados relatam que as pessoas esperam uma resposta, e rápida. O ambiente relatado por esses autores apresenta-se aqui também, uma vez que não há regra formal que exija o monitoramento constante: há uma pressão social externa - aqui representada não apenas por fatores profissionais, como também aspectos pessoais -, que cria expectativa de resposta imediata através da tecnologia (Mazmanian et al., 2006). E essa questão se faz tão presente que a própria tecnologia apresenta cada vez mais elementos que fazem as pessoas mais acessíveis (Yun et al., 2012). Dessa forma, em relação ao aspecto de conexão constante, os recursos que permitem saber quando uma mensagem foi recebida, e até mesmo o dia e a hora em que ela foi lida, deixam as relações de comunicações transparentes e influenciam na 
expectativa alheia de resposta, além de intensificarem esse sentimento que foi classificado como de "urgência", demonstrando que, para essas pessoas, estar constantemente conectado, através das tecnologias móveis, intensificou as comunicações.

Yun et al.(2012) trazem ainda uma figura de linguagem para expressar este aspecto: a porta, no escritório, determinava uma disponibilidade, ou seja, demonstrava quando era possível ou não entrar na sala sem precisar ser anunciado ou sem agendamento prévio. Com o dispositivo móvel, esta porta tornou-se permanentemente aberta, permitindo acesso a qualquer hora do dia ou da noite, sem precisar de qualquer aviso prévio, basta "entrar", através de uma ligação, mensagem de texto ou qualquer outro recurso disponível. Há essa percepção de estar sempre disponível entre os entrevistados (nove de 11):

[BAN01] "Tipo toda hora alguém pode vir falar contigo, é como se tu tivesse que tá sempre ali, entende? E parece às vezes que, como eles podem me perguntar e eu respondo, eles acabam me perguntando de novo se acontecer de novo. E eu falo 'Poxa, já falei isso e isso e isso', mas eles vão lá e me fazem praticamente a mesma pergunta. Isso é bem ruim."

[COR04] "Mas acho que isso aí potencializou com que todos tivessem acesso a muita coisa, esteja onde estiver [...] necessárias e às vezes desnecessárias, antecipa-se muita coisa que poderia ter seu momento mais adequando. [...] A questão da mobilidade é que a conexão, ela é mais rápida, é aquela questão da urgência, então hoje independente da onde eu estiver, literalmente, a gente consegue manter contato com qualquer pessoa onde quer que ela esteja."

Estes entrevistados (nove de 11) também abordaram essa constante conexão que o dispositivo permite em relação aos efeitos que acaba por provocar:

[BAN02] "Eu acho que não me atrapalha, mas eu deixo de fazer muitas coisas em função de estar conectada. De ter esse contato pessoal com as pessoas em função de estar no celular. Porque, né?, tem colegas de trabalho que moram perto da minha casa, então eu deixo de ir conversar com elas pessoalmente e faço isso na minha casa com o telefone."

[CSI] "Sobre a conexão constante, eu não acho muito legal, não. Eu não sei, eu acho mais interessante antigamente, quando não tinha celular, era carta lá, andar a cavalo, tinha um romance maior. Hoje sempre ligado, aí é meio complicado. Perdeu um pouco aquela obrigação de ter que sair com um amigo pra conversar, ir pra um bar, hoje tu faz isso, mas... muitas coisas são puladas por tu tá ali ligado diretamente na pessoa, e com um grupo de amigos, né? [...] Hoje é tudo por celular, tudo instantâneo, eu acho que isso aí tirou um pouco, não sei, o relacionamento das pessoas." 
[CCR] "Eu acho negativo o fato de estar sempre conectado. Em geral, eu acho que as pessoas não têm uma noção clara da necessidade que elas realmente têm de estar atualizando o perfil do Facebook ou olhando o que está acontecendo no Instagram ou vendo todas as conversas em todos os grupos do Whatsapp. Eu acho que as pessoas têm dificuldade de abrir mão disso pra interagir com as pessoas ou passar um final de semana na praia sem olhar o celular. Eu, talvez por ser um pouco mais velho, eu consigo deixar o celular num canto o final de semana inteiro se eu quiser. Mas eu vejo pessoas também da minha idade, mais velhas, que não conseguem, e eu acho meio triste, não sei, acho que falta um pouco de visão, de percepção pras pessoas, porque tu tem que conseguir viver off-line, na minha opinião."

[ESC] "Eu acho que as pessoas têm que tomar um cuidado social, assim, aquela coisa, tá no restaurante e o cara tá vendo as fotos que o fulano postou. Pô, não é a hora, entendeu? E as pessoas também reclamam que todo mundo faz isso e fomentam isso, e fazem. Se no restaurante, tu olha pra mesa do lado, 3, 4, 5 pessoas ao mesmo tempo mexendo no smartphone. Então... Agora, eu acho que isso vai de cada um, também. Eu acho que é um pouco se ligar nas mensagens que estão ao teu redor, tipo, a pessoa que está ali, falando contigo, tá te olhando e tu tá olhando no celular, acho que é um sinal de falta de respeito, coisa assim, eu acho isso essencial."

Apesar de serem questionados a respeito dos efeitos dessa conexão em relação a suas tarefas profissionais, os entrevistados naturalmente relataram sobre sua relação pessoal com a tecnologia, abordando seus efeitos sobre sua percepção em relação aos aspectos sociais. Seus exemplos trazem uma carga forte de percepção negativa sobre o relacionamento social entre as pessoas, demonstrando que a tecnologia móvel para eles inevitavelmente envolve a vida pessoal. Por conter diversas funções intrínsecas, o dispositivo acaba provocando uma mistura entre vida pessoal e vida profissional, sendo difícil encarar essa tecnologia como ferramenta exclusiva de trabalho, ou ferramenta exclusiva de contato social. Mazmanian et al. (2006) relatam que o dispositivo não deixa claro quando é hora de trabalho e quando é hora de lazer, fazendo com que cada indivíduo precise gerenciar essa separação, especialmente em profissões com características autônomas, como os profissionais financeiros pesquisados. A "linha" que separa a vida pessoal e a vida profissional fica cada vez mais difusa, a partir das tecnologias móveis, fazendo com que haja interação entre ambas o tempo inteiro. Um dos aspectos dessa relação difusa é o fato de estar sempre conectado ao trabalho, que também foi aspecto de discussão dos entrevistados (sete de 11): 
[BAN02] "Eu procuro desvincular isso. Senão, como a gente não tem um horário fixo, às vezes... no início, no início, eu tava trabalhando em casa, mas agora eu já procurei desvincular porque senão ficava final de semana direto, não conseguia descansar, ficava só em função do serviço. Então, quando eu chego em casa, eu me desvinculo, os e-mails eu deixo pra olhar no outro dia, quando eu chego no trabalho; eu não olho em casa. Mas ele continua conectado, continua recebendo e-mails, continuo, né?, no aplicativo que a gente tem, fico conversando com as minhas colegas de trabalho, com a minha supervisora, ela manda relatórios pra gente, mas eu procuro não olhar, procuro deixar para o outro dia."

[BAN03] "Eu acho que às vezes é hábito mesmo. É que o alerta em geral faz um alerta, aí eu olho, né? Se eu tô assistindo televisão com o meu filho e aí o telefone acendeu, ele vibrou, eu olho. Às vezes é útil pra lembrar que eu tenho uma reunião no dia seguinte, muitas vezes eu boto o aviso pra noite anterior pra me preparar ou alguma coisa. Agora, com relação a dar continuidade, depende do que é dar continuidade. Teoricamente, se o troço é importante, você deu continuidade na sua cabeça, porque você continuou pensando naquilo. Com relação a fazer algo, com relação a alertas, às vezes, a reunião no dia seguinte é muito importante, o cara tira a noite pra se preparar."

[COR01] "Ah não, sem dúvida, pra responder e-mail dos cotistas é sempre de noite, em geral. Então eu levo pra casa o trabalho. Ah, não é bom, não é a melhor maneira, mas é o que a gente encontra pra poder responder a demanda, então não tem jeito. Hoje infelizmente o fax vai pelo e-mail. Então não tem jeito. Mas eu não considero muito bom, não, sinceramente."

[ESC] "Por muito tempo eu não conseguia colocar essa barreira, e eu era invadido dia e noite. E tô falando assim, de tá trocando e-mail $1 \mathrm{~h}$ da manhã, e o cara responder, e tu falar, putz, eu queria dormir, mas eu sei, eu mandei um e-mail agora e ele vai responder daqui a dois minutos e vai pedir outra coisa e eu vou ter que responder de novo... Eram conversas por e-mail que não acabavam. E às vezes até poderia ter feito por telefone, mas não ia, e ficava tudo ali, registrado, e o cara fazia follow-up: 'Ah, e aquela coisa que tu me prometeu às $2 h$ da manhã aquele dia, cadê?'... Era muito ruim pra mim. Muito ruim."

Através de seus recursos e características, o dispositivo móvel faz com que fronteiras que separam os diferentes momentos do dia do profissional fiquem menos definidas, ou até mesmo não sejam mais percebidas, provocando fusão entre vida pessoal e vida profissional. Yun et al. (2012) destacam esses aspectos reforçando que os indivíduos podem se deparar com conflitos quando o seu ambiente de trabalho invade seu espaço de vida pessoal, assim como quando elementos pessoais surgem ao longo do dia de trabalho.

Segundo Sorensen (2010), não há garantia de harmonia na utilização de tecnologias móveis como formas de interação, uma vez que há imposições inerentes a essas tecnologias. No caso deste estudo, o aspecto de notificações instantâneas pode ser visto como algo que a tecnologia 
móvel impõe, cabendo ao usuário gerir a harmonia desse uso. Há conflitos substanciais nessa relação, uma vez que o dispositivo permite a liberdade de estar em qualquer lugar, ao mesmo tempo que prende, permitindo disponibilidade para interações imediatas (Sorensen, 2010). Os profissionais relataram que as notificações instantâneas influenciam suas tarefas profissionais, especialmente sua concentração:

[ESC] "Sim, eu comecei a limitar as notificações, era um mar de notificações. Basicamente, quando a gente baixa um aplicativo, não vê que tem notificação, até o dia que aquele aplicativo que não tem nada a ver de fotografia não sei o que te notifica que tem uma promoção ou sei lá o que e tu fala 'Pô, que coisa é essa? eu nunca pedi isso aqui'. Aí eu comecei a limitar as notificações, pra ter as mais relevantes."

[COR01] "É, aqui no escritório, todo mundo bloqueia. Até a gente já conversou isso em reunião, celular sempre no silencioso, e notificação de aplicativo a gente bloqueia na central de notificações. Então a gente não fica olhando toda hora. E e-mail também a gente é restrito a olhar duas vezes por dia, pra poder focar."

[COR05] "Normalmente o celular tá em cima da mesa, mas, se eu tenho alguma atividade que eu tenho que me concentrar mais normalmente, eu boto ele dentro da mochila. Porque senão ele pisca ali e tu já se distrai. Acho que é um chamariz. Eu costumo botar, as vezes que eu vejo que eu tô usando muito, eu costumo botar dentro da mochila. Dai fica mais difícil o acesso. Ou dentro da gaveta [risos]."

Os entrevistados relataram que as notificações desse aplicativo atrapalham sua rotina, uma vez que permitem um fácil acesso a qualquer momento, o que corrobora a pesquisa de Sandi e Saccol (2010), que também identificaram a percepção de dificuldade na retomada de concentração após a interrupção provocada por um dispositivo móvel.

Ainda, neste estudo, o principal elemento abordado pelos entrevistados que retrata esse conflito é o Whatsapp. Por sua unanimidade de citação (todos os profissionais referiram-se a ele), optou-se por aprofundar a análise a partir desse aplicativo específico.

Antes de explorá-lo, é importante destacar que não se trata do aplicativo em si, mas sim dos recursos que ele permite ao usuário. Tendo em mente a ideia de que a tecnologia está em constante evolução e aperfeiçoamento, verifica-se a possibilidade de que, ao longo do tempo, novos recursos e funcionalidades sejam integrados ou agregados e resultem em novos tipos de interações, inclusive interações conflituosas. Na realidade inserida, esse aplicativo traz diversos recursos em um só, pois agrega 
várias funcionalidades inerentes aos dispositivos móveis, como mensagens gratuitas diretamente para determinado telefone celular; confirmação de entrega da mensagem; possibilidade de saber quando o outro está online naquele momento; conversas em grupos; notificações a cada nova mensagem; envio de fotos, vídeos e mensagens de voz de forma instantânea, entre outros.

Um dos profissionais [ESC] conseguiu resumir de forma objetiva esse cenário, ao afirmar que "Tu vê, isso é muito dinâmico, há um ano atrás, dois, ninguém tinha grupo de Whatsapp". Assim, quando mencionado o aplicativo Whatsapp, o leitor precisa perceber que não se trata somente do aplicativo em si, mas sim das possibilidades que este traz para a realidade na qual se insere o estudo.

O aplicativo Whatsapp foi mencionado por todos (11 de 11) entrevistados. Durante as entrevistas e observações, também foi possível constatar que todos possuíam o aplicativo e o utilizavam com frequência, durante suas tarefas profissionais e durante as próprias entrevistas. Esse aplicativo carrega uma forte carga pessoal, apesar de também ser utilizado para trabalhar. Durante a realização de tarefas profissionais, é encarado com adjetivos negativos, como "atrapalha" ou "tira a concentração":

[BAN02] "Tira, tira a concentração. Tira redes sociais, essa função de Whatsapp toda hora chamando, tira a minha concentração. Ah, eu costumo responder, eu costumo olhar, não tem como, não consigo... eu costumo olhar. É, tento lidar com o meu trabalho mais tranquila, eu que vou fazendo os meus horários, consigo, mas igual me atrapalha porque tira a minha atenção. Eu poderia estar fazendo coisas do meu trabalho e eu fico olhando o telefone, né? Fico fazendo outras coisas, então eu acho que me atrapalha um pouco."

[COR05] "É, o Whatsapp meu é no mudo, mas fica aparecendo ali a chamada, enfim. Mas não vibra nem faz barulho. Mas, mesmo assim, eu acho que chama. Mas... é mais pra uma questão, mais pra um uso pessoal. Não tanto pra uso profissional. Daí por isso mesmo que eu tiro porque o que tá piscando ali não é tão relevante. Atrapalha a minha concentração."

[COR06] "A maioria eu desligo, as push, né?, a maioria tá desligado, principalmente do Whatsapp. Ah, porque justamente durante o trabalho começa a ficar apitando, apitando, apitando... não tem como. Desligo e olho depois, assim. Porque aqui na mesa, tu tá com as informações ali, tá com o computador ligado, tá recebendo e-mail, então aquilo que é importante, que é relevante pro trabalho tá chegando por ali, né? E aí pra fins profissionais não tem sentido deixar ligado. Tá, ele tá comigo mas assim, aqui na mesa ele fica... ele não fica desligado, mas fica no silencioso, assim, e se precisa, se o telefone toca, a gente precisa sair da mesa pra atender, não pode atender o telefone na mesa de operações. " 
De acordo com Sorensen (2010), no momento em que a tecnologia assume um papel prioritário na interação entre as pessoas, como mediadora desse processo, o equilíbrio entre usuário e tecnologia pode ser afetado caso ela não lhe entregue meios de controle dessa comunicação. Neste estudo, o aplicativo em questão se mostra intrusivo uma vez que fica "apitando", conforme relatado anteriormente por um dos entrevistados [COR06], e acaba por chamar a atenção e tirar a concentração em momentos considerados impróprios. Essa interação é classificada como simétrica, uma vez que a solicitação de comunicação partiu de um terceiro e chegou ao seu destino independentemente de priorização (Sorensen, 2010). Ou seja, foi enviada uma mensagem que chegou ao profissional ainda que não fosse apropriada para aquele momento.

Porém, identifica-se que o próprio aplicativo dispõe de recursos que trazem assimetria e, consequentemente, possibilidade de priorização: a parte remetente escolhe quando é melhor entrar em contato, e a parte receptora pode escolher, neste caso, se será ou não notificada a respeito; também podendo escolher quando acessar aquele conteúdo (Sorensen, 2010). Os entrevistados demonstram conhecer essas ferramentas e utilizálas, o que Ihes permite gerenciar essas interações, transparecendo que cabe a cada usuário conhecer e utilizar da melhor forma esses recursos:

[BAN03] "(...) mas acho que compete à pessoa desativá-las. Eu não acho que é culpa do dispositivo de novo. Eu acho que ou o cara é muito braço curto e não sabe desativar e aí precisa de uma assistência da empresa pra ajudar ele a mexer, ou o cara tem que tomar essa iniciativa. O cara que no trabalho deixa o Whatsapp fazendo barulho com um grupo de amigos, pra mim, é um cara a se cogitar pra ver se ele cabe na empresa. Eu, meu Whatsapp não me avisa nada de grupo, coisa pessoal, só família e trabalho. Tudo que é pessoal fica no mudo, mudo, mudo, leio quando eu quiser, não me pipoca."

[ESC] "Essa coisa de toque também, o Whatsapp tem vários grupos, eu comecei a tirar, diferenciar o toque dos grupos pra toque de pessoas, porque geralmente quando é uma pessoa o assunto tende a ser... não é do grupo, é personalizado, então tende a ser mais importante pra ti, e eu parei com as notificações dos grupos pra cada mensagem que entra. Então, quando eu tô disponível, eu vou lá e vejo 'Ah, tem 80 mensagens desse grupo, beleza', eu vou lá, olho."

[CSI] "Na verdade, o que acontece, já misturando o lado pessoal, mas... Todos os meus grupos de Whatsapp, e grupo do Whatsapp, eu não sei se tu tem algum ou não, não para, né? Quarenta notificações em dois minutos os caras fazem. Esse fica silenciado. Nem aparece na minha área de notificação, ou seja, eu vou ver ao meio-dia, quando eu parar, eu vou abrir 
o grupo pra ver o que eles têm. Eles não despertam e não vêm na área de trabalho, pra não gerar o meu interesse Se alguém mandar diretamente pra mim, porque a gente usa muito o Whatsapp pra trabalhar, esse cara vai vir na minha área de trabalho, na minha notificação no celular."

Os profissionais destacaram, portanto, que o aplicativo em questão acabou provocando um ambiente que destoa e incomoda de certa forma, especialmente por seus recursos de grupo, que não trazem aspectos relevantes naquele momento imediato. Porém o próprio aplicativo dispõe de recursos que permitem suportar o gerenciamento dessas interações, de forma assimétrica (Sorensen, 2010). Assim, foi destacado que cabe ao usuário ter conhecimento e saber gerenciar as diferentes demandas da forma mais adequada não só para ele mesmo, como também para o seu ambiente de trabalho. No Quadro 3, apresentam-se as questões abordadas.

\begin{tabular}{|c|c|c|c|}
\hline Aspecto & $\begin{array}{c}\text { Palavras- } \\
\text { chave }\end{array}$ & Dados & Literatura \\
\hline \multirow[b]{2}{*}{$\begin{array}{l}\text { Conexão } \\
\text { Constante }\end{array}$} & $\begin{array}{l}\text { A tecnologia } \\
\text { móvel trouxe } \\
\text { um maior } \\
\text { sentimento } \\
\text { de urgência }\end{array}$ & $\begin{array}{l}\text { [CSI] Hoje se liga e não atende, te manda } \\
\text { mensagem, Whatsapp, viber... inventa } \\
\text { qualquer coisa pra te achar, tem que te } \\
\text { achar e tu tem que responder rápido. } \\
\text { [ESC] Ninguém tem mais paciência pra } \\
\text { esperar o cara responder } 10 \text { minutos } \\
\text { depois, tem que ser na hora tudo. }\end{array}$ & $\begin{array}{l}\text { Há uma expectativa } \\
\text { de resposta } \\
\text { imediata através da } \\
\text { tecnologia } \\
\text { (Mazmanian et al., } \\
\text { 2006) }\end{array}$ \\
\hline & $\begin{array}{l}\text { A tecnologia } \\
\text { móvel faz } \\
\text { com que } \\
\text { haja uma } \\
\text { constante } \\
\text { disponibili } \\
\text { dade }\end{array}$ & $\begin{array}{l}\text { [BAN01] Tipo toda hora alguém pode vir } \\
\text { falar contigo, é como se tu tivesse que tá } \\
\text { sempre ali, entende? } \\
\text { [COR04] Mas acho que isso aí } \\
\text { potencializou com que todos tivessem } \\
\text { acesso a muita coisa, esteja onde estiver. } \\
\text { [...] necessárias e às vezes } \\
\text { desnecessárias, antecipa-se muita coisa } \\
\text { que poderia ter seu momento mais } \\
\text { adequado. }\end{array}$ & $\begin{array}{c}\text { A conexão } \\
\text { constante impõe } \\
\text { uma disponibilidade } \\
\text { também constante } \\
\text { (Yun et al., 2012) }\end{array}$ \\
\hline \multirow{2}{*}{$\begin{array}{l}\text { Notificações } \\
\text { Instantâneas }\end{array}$} & $\begin{array}{l}\text { A tecnologia } \\
\text { móvel trouxe } \\
\text { aspectos de } \\
\text { conflitos ao } \\
\text { mediar } \\
\text { interações }\end{array}$ & $\begin{array}{l}\text { [ESC] Sim, eu comecei a limitar as } \\
\text { notificações, era um mar de notificações. } \\
\text { [BAN02] Tira, tira a concentração. Tira } \\
\text { redes sociais, essa função de Whatsapp } \\
\text { toda hora chamando, tira a minha } \\
\text { concentração. }\end{array}$ & $\begin{array}{l}\text { Os usuários podem } \\
\text { ter percepções de } \\
\text { dificuldades } \\
\text { relacionadas com o } \\
\text { fluxo de interações } \\
\text { (Sandi \& Saccol, } \\
\text { 2010; Sorensen, } \\
\text { 2010) } \\
\end{array}$ \\
\hline & $\begin{array}{l}\text { A tecnologia } \\
\text { móvel provê } \\
\text { recursos de } \\
\text { assimetria } \\
\text { que } \\
\text { permitem } \\
\text { que o } \\
\text { usuário } \\
\text { gerencie } \\
\end{array}$ & $\begin{array}{l}\text { [BANO3] (...) mas acho que compete à } \\
\text { pessoa desativá-las. Eu não acho que é } \\
\text { culpa do dispositivo de novo. } \\
\text { [CSI] Nem aparece na minha área de } \\
\text { notificação, ou seja, eu vou ver ao meio- } \\
\text { dia, quando eu parar, eu vou abrir o } \\
\text { grupo pra ver o que eles têm. Eles não } \\
\text { despertam e não vêm na área de } \\
\text { trabalho, pra não gerar o meu interesse. }\end{array}$ & $\begin{array}{l}\text { A tecnologia, como } \\
\text { mediadora de } \\
\text { comunicação, } \\
\text { precisa entregar } \\
\text { formas de controle } \\
\text { ao usuário } \\
\text { (Sorensen, 2010) }\end{array}$ \\
\hline
\end{tabular}

\section{Quadro 3: Desenvolvimento dos aspectos de sobrecarga de comunicação}


Fonte: Dados da Pesquisa

A seguir são apresentadas as considerações finais do estudo.

\section{CONCLUSÕES}

Neste estudo, procurou-se apresentar uma discussão a respeito da sobrecarga de comunicação à qual os indivíduos estão expostos, trazendo essa discussão para o campo das tecnologias móveis. Nesse intuito, participaram da pesquisa 11 profissionais do mercado financeiro, usuários de tecnologia móvel e envolvidos em tarefas relacionadas à natureza financeira de sua atividade.

Os objetivos do estudo puderam ser atingidos. Os profissionais pesquisados têm a percepção de que há uma sobrecarga de comunicação. 0 primeiro ponto abordado foi o sentimento de urgência que a facilidade de comunicação através da tecnologia móvel permite. Os entrevistados acreditam que a velocidade da comunicação esteja bastante acelerada, o que faz com que as respostas sejam cobradas em um espaço de tempo cada vez menor. Essa questão corrobora Mazmanian et al. (2006), uma vez que os profissionais demonstram perceber uma crescente expectativa de resposta rápida por parte de seu convívio social, tanto profissional quanto pessoal.

A facilidade de comunicação decorre especialmente do fato de os indivíduos estarem constantemente conectados, o que permite que estejam disponíveis para os outros, a qualquer momento (Yun et al., 2012). Os profissionais entrevistados demonstraram ter essa percepção de estarem sempre disponíveis e destacaram pontos negativos advindos dessa conexão constante. O principal destaque dado foi em relação a sua percepção do convívio social com as pessoas, que não seria mais o mesmo. Apesar de terem sido questionados acerca das atividades profissionais, os entrevistados acabaram relatando pontos pessoais. Segundo Mazmanian et al. (2006), o dispositivo dificulta a separação de momentos de trabalho e momentos de lazer, ou sociais, fato igualmente percebido nos relatos dos entrevistados para este estudo. O dispositivo carrega consigo aspectos pessoais e profissionais ao mesmo tempo, assim, os entrevistados acabam 
por perceber os efeitos dessa sobrecarga de comunicação não exclusivamente para o trabalho, mas inevitavelmente também para sua vida como um todo.

Outro ponto abordado foi a questão das notificações instantâneas. Os profissionais relataram perceber a influência desse recurso da tecnologia móvel ao longo de seu dia de trabalho, especialmente em relação a sua concentração nas tarefas. Conforme pode ser observado na pesquisa, os profissionais financeiros estão envolvidos com uma rotina de concentração e estudo de relatórios, observação do comportamento dos mercados e leitura. Percebeu-se nos relatos que as notificações que piscam na tela tiram a atenção do profissional naquele momento, o que pode ocasionar perda de concentração na atividade inicial. Ao afirmarem que os profissionais pesquisados percebem a influência negativa dessas notificações durante a realização de suas tarefas profissionais, esses relatos corroboram a pesquisa de Sandi e Saccol (2010).

Segundo Sorensen (2010), uma vez que a tecnologia assume papel principal ao mediar a comunicação, não se pode garantir a harmonia da relação usuário-tecnologia, justamente por imposições específicas que esta acaba provocando. Os profissionais entrevistados relataram sua percepção de que este aplicativo, permitindo interação especialmente entre mais de uma pessoa ao mesmo tempo (os chamados grupos do Whatsapp) acabam trazendo uma grande quantidade de interação que nem sempre é conveniente naquele momento.

O próprio aplicativo, e o dispositivo móvel, por sua vez, trazem recursos de bloqueio que permitem a priorização e a personalização dessas notificações, além da escolha daquelas que serão ou não mostradas, com ou sem barulho, dentre outros recursos, trazendo assimetria e possibilidade de escolha para esses profissionais (Sorensen, 2010). Os entrevistados relataram utilizar esses recursos e que, graças a essas possibilidades, há um convívio com mais equilíbrio, e o aplicativo é utilizado, também, durante as atividades profissionais; porém cabe ao usuário gerenciá-lo e configurálo da forma que melhor Ihe convier.

A sobrecarga de comunicação tratou da participação do dispositivo móvel como mediador de comunicação, e todas as implicações que dela 
podem ser derivadas. A constante disponibilidade que o dispositivo traz, permitindo que as pessoas estejam sempre acessíveis, provoca uma sensação de urgência e traz por vezes a expectativa de resposta imediata, independentemente de dia ou horário (Mazmanian et al., 2006). Com isso, puderam ser observados conflitos que o dispositivo trouxe, por provocar distração, perda da concentração e ainda um alto volume de comunicação, em nível considerado excessivo na percepção dos profissionais. Porém, foi destacado também que o dispositivo entrega ao usuário formas de gerenciar essas interações, permitindo assimetria e colaborando para maior harmonia entre o dispositivo e os profissionais (Sorensen, 2010).

Eis alguns limites da pesquisa: não foi possível ficar o mesmo espaço de tempo com todos os participantes, tendo esse intervalo variado entre duas e seis horas. Em relação à análise dos dados, não houve análise que permitisse verificar especificidades sociodemográficas (devido a fatores como faixa etária homogênea, gênero predominantemente masculino, tempo de mercado na faixa de oito anos, entre outros) em relação às sobrecargas aqui estudadas. Uma pesquisa com maior quantidade de profissionais poderá permitir estudar grupos em relação a diferentes características e trazer olhares mais específicos para a temática.

A seleção de um mercado específico (financeiro) pode não evidenciar outros aspectos que eventualmente seriam também relevantes para a melhor compreensão sobre o tema. Assim, sugere-se pesquisa futura que possa evidenciar os mesmos pontos aqui tratados através da ótica de profissionais de outros setores, uma vez que suas particularidades podem agregar mais elementos de análise. Um exemplo seriam os desenvolvedores de software, dada a natureza analítica de suas tarefas, que exige concentração e atenção. Ainda, sendo as temáticas de pesquisa dinâmicas, podem ser agregadas outras perspectivas para discorrer a respeito da sobrecarga de comunicação, ao longo do desenvolvimento de outros estudos. 


\section{REFERÊNCIAS}

Ark, W. S., \& Selker, T. (1999). A look at human interaction with pervasive computers. IBM System Journal, 38(4), 504-507.

Associação Brasileira das Entidades dos Mercados Financeiro e de Capitais Anbima (2013). Certificação. Recuperado em 21 de novembro, 2013, de http://portal.anbima.com.br/produtos-eservicos/certificacao/Pages/certificacao.aspx

Bawden, D., \& Robinson, L. (2009). The dark side of information: overload, anxiety and other paradoxes and pathologies. Journal of Information Science, 35(2), 180-191.

Bharadwaj, A., Sawy, O., Pavlou, P., \& Venkatraman, N. (2013, June). Digital business strategy: toward a next generation of insights. Management Information System Quarterly - MISQ, 37(2), 471-482.

Bittman, M., Brown, J. E., \& Wajcman, J. (2009). The mobile phone, perpetual contact and time pressure. Work Employment Society, 23(4), 673-691.

Büscher, M., \& Urry, J. (2009). Mobile methods and the empirical. European Journal of Social Theory, 12(1), 99-116.

Cohen, S. (1980). Aftereffects of stress on human performance and social behavior: a review of research and theory. Psychological Bulletin, 88(1), 82-108.

Davenport, T. H., \& Beck, J. C. (2002). The attention economy: understanding the new currency of business. Cambridge, MA: Harvard Business School Press.

Delone, W. H., \& McLean, E. R. (2003). The DeLone and McLean model of information systems success: a ten-year update. Journal of Management Information Systems, 19(4), 9-30.

Drucker, P. F. (1970). Prática de administração de empresas (vol. 2, 4a ed.). Rio de Janeiro: Fundo de Cultura.

Dourish, P. (2004). What we talk about when we talk about context. Personal and Ubiquitous Computing, 8(1), 19-30.

Eppler, M. J, \& Mengis, J. (2004). The concept of information overload: a review of literature from organization science, accounting, marketing, MIS, and related disciplines. The Information Society, 20(5), 325-344.

Folha de S.Paulo. (2013, junho 6). Bolsa brasileira fecha em queda de $3 \%$ e atinge menor nível desde agosto de 2011. Recuperado em 9 de julho, 2013, de http://www1.folha.uol.com.br/mercado/2013/06/1293460bolsa-brasileira-fecha-em queda-de-3-e-atinge-menor-nivel-desdeagosto-de-2011.shtml 
Forbes. (2013, April 11). Bring your own device: in 2013 there will be more mobile devices than people on earth. Recuperado em 22 de abril, 2013, de http://www.forbes.com/sites/tjmccue/2013/04/11/bring-your-owndevice-in-2013-there-will-be-more-mobile-devices-than-people-on-earth

Freitas, H., \& Moscarola, J. (2002). Da observação à decisão: métodos de pesquisa e de análise quantitativa e qualitativa de dados. RAE Eletrônica, 1(1), 1-29.

Hadar, L., Sood, S., \& Fox, C. (2013). Subjective knowledge in consumer financial decisions. Journal of Marketing Research, 50(3), 303-316.

Instituto Brasileiro de Certificação de Profissionais Financeiros - IBCPF. (2013). O Planejador Financeiro. Recuperado em 18 de julho, 2013, de http://www.ibcpf.org.br/PlanejadorFinanceiro/O-que-e

Jarvenpaa, S. L., \& Lang, K. R. (2005). Managing the paradoxes of mobile technology. Information System Management, 22(4), 7-23.

Kakihara, M., \& Sorensen, C. (2001, December). Expanding the 'mobility' concept. SIGGROUP Bulletin, 22(3), 33-37.

Karr-Wisniewski, P., \& Lu, Y. (2010). When more is too much: operationalizing technology overload and exploring its impact on knowledge worker productivity. Computers in Human Behavior, 26(5), 1061-1072.

Ladd, D. A., Datta, A., Sarker, S., \& Yu, Y. (2010). Trends in mobile computing within the IS discipline: a ten-year retrospective. Communications of the Association for Information Systems, 27(1), 285306.

Lemos, A. (2007). Cidade e mobilidade: telefones celulares, funções pósmassivas e territórios informacionais. MATRIZes, 1(1), 121-137.

Malhotra, N. (2012). Pesquisa de marketing: uma orientação aplicada (6a ed). Porto Alegre: Bookman.

Mazmanian, M. A., Orlikowski, W. J., \& Yates, J. (2005). Crackberries: the social implications of ubiquitous wireless e-mail devices. In C. Sorensen, Y. Yoo, K. Lyytinen, \& J. I. DeGross, Designing ubiquitous information environments: socio-technical issues and challenges (pp. 337-343). New York: Springer.

Mazmanian, M., Yates, J., \& Orlikowski, W. (2006). Ubiquitous email: individual experiences and organizational consequences of Blackberry use. Academy of Management Proceedings, 2006(1), D1-D6.

Mintzberg, H. (1984). Le manager au quotidien: les dix rôles du cadre. Paris: Les Éditions D'Organisation.

Orlikowski, W. J. (2007) Sociomaterial Practices: Exploring Technology at Work. Organization Studies, 28 (09), 1435 - 1448. 
Pica, D., Sorensen, C., \& Allen, D. (2004). On mobility and context of work: exploring mobile police work. Proceedings of the Hawaii International Conference on System Sciences - HICSS, 37, Hawaii, USA.

Póvoa, A. (2010). Mundo financeiro: um olhar de um gestor. São Paulo: Saraiva.

Saccol, A. Z., \& Reinhard, N. (2007). Tecnologias de informação móveis, sem fio e ubíquas: definições, estado-da-arte e oportunidades de pesquisa. Revista de Administração Contemporânea - RAC, 11(4), 175198.

Sandi, L. B., \& Saccol, A. Z. (2010). Sobrecarga de informações geradas pela adoção de tecnologias da informação móveis e sem fio e suas decorrências para profissionais de vendas. Revista Eletrônica de Sistemas de Informação, 9(2), 1-23.

Schroeder, R. (2010). Mobile phones and the inexorable advance of multimodal connectedness. New Media Society, 12(1), 75-90.

Sorensen, C. (2010). Cultivating interaction ubiquity at work. The Information Society, 26(4), 276-287.

Weiser, M. (1991, September). The computer for the twenty-first century. Scientific American, 265(3), 94-104.

Yun, H., Kettinger, W. J., \& Lee, C. C. (2012). A new open door: the smartphone's impact on work-to-life conflict, stress, and resistance. International Journal of Electronic Commerce, 16(4), 121-151.

Yin, R. K. (2010). Estudo de caso: planejamento e métodos (4a ed.). Porto Alegre: Bookman.

Zhong, B. (2013). From smartphones to iPad: power users' disposition toward mobile media devices. Computers in Human Behavior, 29(4), 1742-1748. 